\title{
Correction to: Fractionated ifosfamide, carboplatin, and etoposide with rituximab as a safe and effective treatment for relapsed/refractory diffuse large B cell lymphoma with severe comorbidities
}

\author{
Norina Tanaka ${ }^{1} \cdot$ Yoichi Imai $^{2} \cdot$ Kentaro Yoshinaga ${ }^{1}$ Masayuki Shiseki ${ }^{1} \cdot$ Junji Tanaka $^{1}$ \\ Published online: 26 September 2020 \\ (C) Springer-Verlag GmbH Germany, part of Springer Nature 2020
}

Correction to: Annals of Hematology

https://doi.org/10.1007/s00277-020-04267-0

In the published online paper, the data " $p=0.144$ " was not deleted from the line "Median and mean number of prior treatments (range)" in Table 4. The publisher wish to apologize for this oversight.

The original article has been corrected.

Publisher's note Springer Nature remains neutral with regard to jurisdictional claims in published maps and institutional affiliations.

The online version of the original article can be found at https://doi.org/ $10.1007 / \mathrm{s} 00277-020-04267-0$

Yoichi Imai

imaiyo-tky@umin.ac.jp

1 Department of Hematology, Tokyo Women's Medical University, Tokyo, Japan

2 Department of Hematology/Oncology, Research Hospital, Institute of Medical Science, University of Tokyo, 4-6-1, Shirokanedai, Minato-ku, Tokyo 108-8639, Japan 